\title{
Caracterización de los semilleros de investigación en los programas de contaduría pública en Colombia ${ }^{1}$
}

\author{
Mayra Alejandra Hoyos Calderón ${ }^{2}$ \\ Maritza Rocha Rodríguez $3^{3}$ \\ Oscar Yamith Duque Cruz ${ }^{4}$ \\ Jeniffer Paola Rodríguez Garay \\ Sonia Milena Gómez Ramírez ${ }^{6}$ \\ Paola Andrea Leiva Soto ${ }^{7}$
}

1 Artículo resultado de la investigación titulada bajo el mismo nombre y presentada en la Octava Convocatoria General para el Fomento, Desarrollo y Producción de la Investigación de Alto Nivel de la Universidad Santo Tomás (FODEIN), 2014, realizada por el Semillero de investigación en Educación y Teoría Contable (SINETCO). Se contó con la colaboración especial de la profesora Gloria Milena Valero Zapata y las estudiantes Mayra Alejandra Hoyos Calderón y Sonia Milena Gómez Ramírez en la etapa de estructuración y presentación del proyecto.

2 Economista y contadora de la Universidad Santo Tomás. Docente de la Corporación Universitaria Minuto de Dios, Facultad de Contaduría Pública UVD.

3 Estudiante de décimo semestre de Contaduría Pública de la Universidad Santo Tomás, Bogotá. Integrante del Semillero de Investigación en Educación y Teoría Contable (SINETCO).

4 Administrador de empresas de la Universidad Antonio Nariño. Magíster en Educación de la Universidad Santo Tomás. Docente-coordinador del Semillero de Investigación en Educación y Teoría Contable(SINETCO), Facultad de Contaduría Pública de la Universidad Santo Tomás, Bogotá.

5 Estudiante de séptimo semestre de Contaduría Pública de la Universidad Santo Tomás, Bogotá. Integrante del Semillero de Investigación en Educación y Teoría Contable (SINETCO).

6 Contadora pública de la Universidad Santo Tomás, Bogotá. Integrante del Semillero de Investigación en Educación y Teoría Contable (SINETCO).

7 Estudiante de séptimo semestre de Contaduría Pública de la Universidad Santo Tomás. Integrante del Semillero de Investigación en Educación y Teoría Contable (SINETCO). 
Recibido: 18 de julio de 2014

Aprobado: 17 de octubre de 2014

Hoyos, M., Rocha, M., Duque, O., Rodríguez, J., Gómez, S. \& Leiva, O. (2014). Caracterización de los semilleros de investigación en los programas de contaduría pública en Colombia. Activos 23, 133-181

Clasificación JEL: A22

\title{
Resumen
}

Este artículo se desarrolló a partir del interés por conocer los aspectos que identifican los semilleros de las facultades de contaduría pública en el país, relacionados con sus integrantes, líneas de investigación, productividad, financiación y capacitación. Se tomó como base una muestra de programas académicos a escala nacional, y se utilizó un abordaje metodológico tanto cuantitativo como cualitativo, a través de dos modelos de encuestas dirigidas a docentes y estudiantes. Esto permitió identificar las principales características de un total de veinte semilleros de investigación activos.

\section{Palabras clave}

Semilleros, caracterización, educación contable, contaduría pública.

Hoyos, M., Rocha, M., Duque, O., Rodríguez, J., Gómez, S. \& Leiva, O. (2014). Characterizacion of the research seedbeds in public accounting programs in Colombia. Activos 23, 133-181

\begin{abstract}
This article was developed from the interest to know the aspects that identify the seedbeds of the faculties of public accounting in the country,
\end{abstract}


regarding its members, research lines, productivity, financing and training. A sample of the academic programs at national level was taken as basis, and a quantitative and qualitative methodological approach was used, through two models of surveys addressed to teachers and students. This allowed us to identify the main features of a total of twenty active research seedbeds.

\section{Keywords}

Costs accounting, management accounting, direct or variable costing methods, full or absorption costing methods.

\section{Hoyos, M., Rocha, M., Duque, O., Rodríguez, J., Gómez, S. \& Leiva, $O$. (2014). Détermination des groupes de recherche au sein des pro- grammes de comptabilité publique en Colombia. Activos 23, 133-181}

\section{Résumé}

Cet article s'est construit à partir de l'intérêt pour connaitre les aspects qui identifient les groupes de recherche des facultés de comptabilité publique en Colombie, en relation avec ses intégrants, ses domaines de recherche, productivité, financement et formation. Un échantillon de programmes académiques au niveau national a été défini comme base de l'étude, privilégiant un aspect méthodologie quantitatif et qualitatif, à travers de deux modèles d'enquête dirigés aux professeurs et aux étudiants. Ceci a permis d'identifier les principales caractéristiques d'un total de 20 groupes de recherche actifs.

\section{Mots clés}

Groupe de recherche, détermination, éducation comptable, comptabilité publique. 


\section{Introducción}

A partir de una revisión sobre las cifras asignadas a la investigación en Colombia, se encuentran los siguientes datos: para 2012, la población total era de 46,5 millones de habitantes; En 2008 y 2009 la cifra estaba alrededor de 44,4 millones (Banco de la República, s. f.). Según estos datos, en 2009, por cada millón de habitantes existían 161 personas dedicadas a la investigación, profesionales trabajando en la creación de "nuevos conocimientos, productos, procesos, métodos o sistemas, y a la gestión de los proyectos correspondientes. Se incluyen los estudiantes de doctorados [...] dedicados a investigación y desarrollo" (Banco Mundial, s. f.).

Para ese mismo periodo se publicaron en Colombia 168 artículos, en medios científicos y técnicos, en las siguientes áreas: "física, biología, química, matemática, medicina clínica, investigación biomédica, ingeniería y tecnología, y ciencias de la tierra y el espacio (Banco Mundial, s. f.). Por ello, diversos actores de la comunidad académica están incentivando la investigación a través del apoyo "a quienes desde edad temprana sientan su interés en la investigación como parte de sus proyectos de vida, integrándose y conformando Semilleros de Investigación" (Vivas, 2010, p. 11).

En Colombia, este proyecto surge en la década de los noventa, particularmente en la Universidad de Antioquia, "como una estrategia extra curricular de fomento de la investigación y como una reacción a las formas de impulso a esta función básica de la educación superior, institucionalizadas por la propia Universidad e impulsadas por Colciencias" (Rojas, 2010, p. 5).

El proyecto iniciado en la Universidad de Antioquia es la base para sustentar que en más de 220 instituciones de educación superior (IES) se han formado semilleros de investigación, en los que se desarrollan actividades de manera continua. Así, se logró la consolidación de la Red Colombiana de Semilleros de Investigación (RedCOLSI) y la dinámica de los nodos regionales (Rojas, 2010, p. 5). 
Estos grupos se crean fundamentalmente para incentivar a los niños, jóvenes y docentes a cambiar su pensamiento acerca de la investigación, para que de esta forma, desde temprana edad, empiecen a indagar el porqué de las cosas o cuál es la causa que originó determinado problema. “[...] con esto, se busca que los Semilleros de Investigación sean el eslabón entre el pregrado y los niveles de formación en maestría, en una cadena de formación en investigación que debe abarcar desde el preescolar hasta el nivel doctoral" (Fernelly, citado en Hernández, 2005, p. 4).

En 2007 se evidenció un incremento en los semilleros de investigación, a partir de la convocatoria realizada por la Universidad Católica de Manizales, en la cual se "presentaron 110 ponencias y 375 inscripciones procedentes de 22 universidades e instituciones de educación media básica, de las cuales 70 ponencias fueron seleccionadas para el X Encuentro Nacional" (Quintero, Munévar y Munévar, 2008). Estos semilleros privilegian la participación de los estudiantes, de forma crítica y constructiva, en los problemas económicos, sociales y ambientales, entre otros; "fortaleciendo las capacidades investigativas para la toma de decisiones" (Torres, 2005, p. 3). En cuanto a la investigación contable, Ariza (citado en Gómez, 2003) afirma que

Será el camino para reforzar una perspectiva disciplinar de la contabilidad, que permita hacer trascender a nuestros profesionales de la repetición mecánica, autista y autómata de registros contables, a una comprensión profunda y sustancial de la realidad que miden, representan y controlan, que en todo caso se refiere a relaciones técnicas de producción y sociales de distribución (p. 141).

Se evidencia así la utilidad de la investigación en contaduría, dado que esta es marcada como una profesión mecánica, en donde prevalece el que hacer y no la comprensión y el análisis. De esta forma el estudiante, con la ayuda del docente, podrá desarrollar habilidades como la observación, la comprensión, el análisis, la crítica, la redacción, entre otras, que utilizará en el desarrollo de las actividades laborales. 
Teniendo en cuenta la importante difusión y acogida de los grupos de semilleros de investigación, particularmente en las facultades de contaduría pública, surgió la necesidad de identificarlos, así comosus productos, las características de sus integrantes y las condiciones institucionales para su conformación y consolidación. Esto, a partir de la comprensión de que los semilleros en Colombia, según Colciencias (citado en Patiño y Santos, 2009, p. 28), son "una estrategia pedagógica extracurricular que tiene como finalidad fomentar la cultura investigativa en estudiantes del pregrado que se agrupan para desarrollar actividades que propendan por la formación investigativa, la investigación formativa y el trabajo en red".

Por lo anterior, los semilleros de investigación contribuyen en los procesos de enseñanza-aprendizaje, de forma colaborativa, al garantizar aportes que son transversales a lo académico, lo profesional y lo personal. Para la comunidad estudiantil contable no es solo un proceso que contribuye con la formación técnica que se suele resaltar de la profesión contable, sino un elemento potenciador de investigación formativa y del desarrollo de habilidades como la comprensión y el análisis.

El mayor beneficiado con los resultados de este tipo de investigaciones es sin duda la comunidad académica, pues para muchos estudiantes es desconocido el tema de los semilleros de investigación. ¿Qué es un semillero?, ¿qué actividades realiza un semillero?, ¿qué temas se investigan en un semillero? Son algunas de las preguntas que surgen.

Cuando se plantea un semillero dentro de una facultad de contaduría, la principal pregunta gira en torno a la posibilidad de investigar desde conocimientos que aún no se tienen desde lo contable, pues son temas que a pesar de su relevancia, no se ven en las clases - o que cuando se ven, son de gran interés para los estudiantes, por lo que estos se animan a investigar-. Por esta razón, el trabajo fue identificar y caracterizar los semilleros de investigación activos en las facultades de contaduría pública del país, con el fin de producir una fuente útil para la creación de nuevos e incentivar, de esta forma, la investigación. Adicionalmente, la elaboración 
de una base de datos facilitará el desarrollo de investigaciones interinstitucionales (entre semilleros).

Todo lo anterior, con el fin de incrementar el nivel investigativo en los estudiantes de diferentes carreras, especialmente la contable, no solo por el hecho de recopilar hallazgos e información sobre temas de importancia, sino también para que los estudiantes mismos conozcan más de su carrera e indaguen. Además, es de suma importancia que el estudiante tenga conocimiento sobre estas actividades extracurriculares que brinda cada facultad o programa en las universidades, pues los semilleros y grupos de investigación, además de abrir espacios de comunicación estudianteestudiante y estudiante-docente, permiten el intercambio de conocimientos en las diferentes áreas que integran la contabilidad.

Es importante resaltar que no se encontraron investigaciones relacionadas con los semilleros de las facultades de contaduría pública, diferentes a la presentada por Hoyos (2013), la cual pretendía, con relación al tema:

[inicio de cita] Concluir sobre cuatro aspectos: [1] ¿Quién es el profesional integral?, [2] ¿cuáles son los semilleros de investigación pertenecientes a los programas de contaduría pública con acreditación de alta calidad en la ciudad de Bogotá?, [3] conocer las líneas de investigación que desarrollan los grupos objeto de estudio, [4] determinar los aportes que da la investigación en el desarrollo de la formación integral (p. 2).

Ahora bien, al revisar la producción relacionada con las facultades de contaduría pública y sus semilleros o grupos dedicados a la investigación formativa, no se evidencia un documento consolidado que muestre lo que ha hecho cada uno de estos grupos; sin embargo, se tiene conocimiento sobre los desarrollos investigativos en el momento en que se socializan las investigaciones en congresos de estudiantes, o se escriben documentos en revistas académicas, pero aún no hay un instrumento que permita presentar estos resultados. 
En la ponencia: Incidencia de los semilleros de investigación en la formación integral del contador público, elaborada por Hoyos (2013), se generó un avance en la consolidación de los resultados de los semilleros de las facultades de contaduría pública acreditadas en la ciudad de Bogotá. Dichos resultados se observan en la tabla 1 .

Tabla 1. Características de los semilleros de investigación en las universidades encuestadas

\begin{tabular}{|c|c|c|c|c|}
\hline Universidad & Semillero & $\begin{array}{c}\text { Tiempo } \\
\text { de } \\
\text { formación }\end{array}$ & $\begin{array}{c}\text { Líneas } \\
\text { de } \\
\text { investigación }\end{array}$ & $\begin{array}{c}\text { Otras } \\
\text { disciplinas } \\
\text { relacionadas } \\
\text { con los } \\
\text { semilleros } \\
\text { contables }\end{array}$ \\
\hline \multirow{3}{*}{$\begin{array}{l}\text { Universidad } \\
\text { Militar Nueva } \\
\text { Granada }\end{array}$} & \multirow{3}{*}{$\begin{array}{l}\text { Grupo de } \\
\text { Estudios } \\
\text { Contemporaneos } \\
\text { en Contabilidad } \\
\text { Gestión y } \\
\text { Organización }\end{array}$} & \multirow{3}{*}{8 años } & Competitividad & Economía \\
\hline & & & $\begin{array}{l}\text { Responsabilidad } \\
\text { social } \\
\text { empresarial }\end{array}$ & Administración \\
\hline & & & $\begin{array}{l}\text { Estudios } \\
\text { contables y } \\
\text { liderazgo }\end{array}$ & $\begin{array}{l}\text { Contaduría } \\
\text { Pública }\end{array}$ \\
\hline \multirow{2}{*}{$\begin{array}{l}\text { Fundación } \\
\text { Universitaria } \\
\text { Central }\end{array}$} & \multirow[b]{2}{*}{ Campo Contable } & \multirow[b]{2}{*}{3 años } & $\begin{array}{l}\text { Conocimiento } \\
\text { contable }\end{array}$ & \multirow{2}{*}{$\begin{array}{l}\text { Todos los } \\
\text { programas que } \\
\text { deseen participar }\end{array}$} \\
\hline & & & $\begin{array}{l}\text { Teoría y } \\
\text { pensamiento } \\
\text { contable }\end{array}$ & \\
\hline \multirow{2}{*}{$\begin{array}{l}\text { Universidad } \\
\text { Santo Tomás }\end{array}$} & \multirow{2}{*}{$\begin{array}{l}\text { Semillero en } \\
\text { Educación y } \\
\text { Teoría Contable } \\
\text { (SINETCO) }\end{array}$} & \multirow{2}{*}{11 meses } & $\begin{array}{l}\text { Desarrollo } \\
\text { sostenible }\end{array}$ & \multirow{2}{*}{$\begin{array}{l}\text { Contaduría } \\
\text { Pública }\end{array}$} \\
\hline & & & $\begin{array}{l}\text { Educación } \\
\text { contable }\end{array}$ & \\
\hline
\end{tabular}

Fuente: Hoyos (2013). 
Según esta investigación, el 31 \% de las facultades de contaduría pública acreditadas en el país se encuentran en la ciudad de Bogotá y corresponden a siete universidades. De estas se logró recolectar información de tres, puesto que las otras cuatro, a pesar de ser contactadas, no participaron de la investigación.

Lo anterior permitió evidenciar la inexistencia de una red de investigación formativa en las facultades de contaduría pública, y aun cuando se desarrollan investigaciones que se socializan en los congresos y diversos eventos investigativos en los que participan diferentes estudiantes, no existe una comunicación eficaz sobre estas investigaciones.

Teniendo en cuenta la evolución que han tenido los semilleros de investigación en diferentes áreas del conocimiento, entre ellos el contable, fue necesario preguntarse ¿cuáles son las principales características de los semilleros de investigación activos de las facultades de contaduría pública en Colombia?

\section{Objetivo general}

Caracterizar los semilleros de investigación activos en las facultades de contaduría pública en Colombia.

\section{Objetivos específicos}

- Identificar los semilleros de investigación activos en las facultades de contaduría pública en Colombia.

- Determinar las principales características de los semilleros de investigación activos en relación con: integrantes, líneas de investigación, productividad, financiación y capacitación.

- Construir una base de datos sobre los semilleros de investigación objeto de estudio. 


\section{Aspectos teórico-conceptuales}

La existencia de los semilleros de investigación, más que una iniciativa de las universidades o de los estudiantes, ha estado implícitamente presionada por las exigencias normativas del gobierno nacional. Según Torres (2005), solo se reconocerán como universidades las instituciones que dentro de un proceso de acreditación muestren tener un alto nivel de experiencia en investigación; de esta manera, las universidades deben promover los semilleros de investigación que cuenten con la participación de alumnos en la gestión de proyectos de investigación de diferente índole, unidos con la formación profesional. Por tal razón se tiene como referencia normativa inicial el Decreto 80 de 1980, el cual vincula tres aspectos clave para los currículos: "el investigativo, el de formación social-humanística y el de formación profesional” (Quintero, Ancízar y Munévar, 2008). En la tabla 2 se presentan los fundamentos normativos en Colombia que están directamente relacionados con la aparición de la figura de los semilleros de investigación.

Tabla 2. Normatividad colombiana relacionada con los semilleros de investigación

\begin{tabular}{l|l}
\hline \multicolumn{1}{c|}{ Normas } & \multicolumn{1}{c}{ Descripción } \\
\hline $\begin{array}{l}\text { Ley 30 de 1992 } \\
\begin{array}{l}\text { Por la cual se organiza el servicio } \\
\text { público de la educación superior. }\end{array}\end{array}$ & $\begin{array}{l}\text { Profundizar en la formación integral, } \\
\text { que permita que el estudiante pueda } \\
\text { capacitarse para cumplir las funciones } \\
\text { profesionales, investigativas y de servicio } \\
\text { social que requiere el país, transmitiendo y } \\
\text { creando nuevas culturas de conocimiento } \\
\text { a la sociedad. }\end{array}$ \\
\hline $\begin{array}{l}\text { Decreto 2566 de 2003 } \\
\text { con la cual se establecen las } \\
\text { educación superior. }\end{array}$ & $\begin{array}{l}\text { La institución debe desarrollar la cultura } \\
\text { investigativa, el pensamiento crítico, en la } \\
\text { comunidad académica. }\end{array}$ \\
\hline $\begin{array}{l}\text { Resolución 3459 de 2003 } \\
\text { Por la cual se definen las características } \\
\text { especificas de calidad para los } \\
\text { programas de pregrado de contaduría } \\
\text { pública. }\end{array}$ & $\begin{array}{l}\text { Formación socio humanista, la cual } \\
\text { comprende saberes y prácticas que } \\
\text { complementan la formación integral del } \\
\text { contador público. }\end{array}$ \\
\hline
\end{tabular}




\begin{tabular}{l|l}
\hline \multicolumn{1}{c|}{ Normas } & \multicolumn{1}{c}{ Descripción } \\
\hline $\begin{array}{l}\text { Ley 1188 de 2008 } \\
\text { Por la cual se regula el registro } \\
\text { calificado de programas de } \\
\text { educación superior y se dictan otras } \\
\text { disposiciones. }\end{array}$ & $\begin{array}{l}\text { Condiciones mínimas de calidad: } \\
\text { - Adecuada formación en investigación. } \\
\text { docencia, investigación y extensión. }\end{array}$ \\
\hline
\end{tabular}

Fuente: Hoyos (2013).

Por otro lado, el gobierno nacional ha venido incentivando la ciencia, la tecnología y la innovación (CTI), mediante propuestas que buscan "crear las condiciones para que el conocimiento sea un instrumento del desarrollo, es decir, la construcción y siembra de un mejor futuro para los colombianos" (Colciencias, 2008, p. 61), de forma que se garanticen aspectos relacionados con instrumentos de fomento a la investigación y la innovación.

Las IES han hecho énfasis en el desarrollo y la evolución de asignaturas relacionadas con la investigación y obtención de nuevos conocimientos, que le permitan a la comunidad facilitar, proponer o divulgar soluciones a las problemáticas presentadas en el entorno académico y laboral, no solo relacionado con el campo contable, sino también en diferentes temáticas que le permitan al individuo formarse como ciudadano (Patiño y Santos, 2009).

Además, los procesos desarrollados por las IES están ligados a una determinada regulación que les proporciona una serie de parámetros y límites para el desarrollo del proceso de enseñanza-aprendizaje, de acuerdo con las características del entorno y sus requerimientos. Con el cumplimiento y aplicación de dichos parámetros, y el establecimiento de otros por parte de las IES, de acuerdo al Ministerio de Educación Superior (2010), estas pueden contribuir al mejoramiento de la calidad en la educación superior y la obtención del reconocimiento público, por parte del Estado, como institución de alta calidad, que permite generar credibilidad en el trabajo $y$, por ende, propiciar el reconocimiento de sus logros. 
Las IES han procurado proveer las herramientas necesarias para el desarrollo de una educación de calidad, mediante la aplicación de las funciones universitarias relacionadas con la docencia, la investigación y la proyección social. Para este estudio, es necesario identificar el termino de investigación como "el procedimiento reflexivo, sistemático, controlado y crítico que tiene por finalidad descubrir o interpretar los hechos y fenómenos, relaciones y leyes de un determinado ámbito de la realidad" (Grajales, 2000, p. 1).

Sin embargo, en el campo educativo surge el término de investigación formativa, entendida como una función pedagógica que permite que los actores involucrados puedan interactuar y trabajar activamente en la generación de conocimientos que aporten a la sociedad en general, y que ayuden a explorar nuevas relaciones entre los estudiantes y su entorno, además de formar profesionales críticos, capaces de comprender mejor el contexto nacional frente al internacional, de forma tal que se motive su curiosidad y capacidad de asombro (Restrepo, 2010). Adicionalmente, la investigación formativa pretende que a partir de la relación existente en el aula de clase, los estudiantes enuncien problemas que identifiquen en la sociedad, para resolverlos mediante el desarrollo de competencias científicas y profesionales (Gonzalez, 2005).

El interés por parte de algunos estudiantes ha permitido crear grupos de investigación en las diferentes facultades y programas de educación superior. Dichos grupos se denominan semilleros de investigación, y se implementan como una estrategia de iniciación temprana en el campo de la investigación, orientada por uno o varios docentes que proporcionan las herramientas necesarias para el desarrollo eficiente y eficaz de un proceso de investigación disciplinar o interdisciplinar, en el cual es importante la crítica, la creatividad y el ingenio de sus miembros.

Según Quintero y Munévar (2008), los semilleros aparecen como un espacio en el cual los estudiantes involucrados en el trabajo de un investigador (tutor) logran crear un conjunto de comunidades de aprendizaje, a través de un tema específico y de la busqueda de recursos para mantener vigente la investigación. 
Por lo anterior, es relevante mencionar que uno de los principales propósitos de los semilleros de investigación está asociado a la formación integral y a la investigación, "pero no de forma aislada, sino en mutua relación y articulación con propuestas curriculares tendientes a reforzar la formación en investigación en todos los niveles del sistema educativo" (Zuluaga, Mosquera e Higuera, 2012, p. 41). Sin embargo, para ello se requiere el trabajo mancomunado de los diferentes actores de la cultura contable $^{8}$, a través de diversas estrategias y medios, tales como: "El apoyo a la formación de alto nivel de los investigadores, especialmente los profesores de planta que los conforman (sic)[...]) el incremento de la interacción entre los procesos de investigación y los de formación del talento humano" (Pineda, 2009). Nuevamente en que se diferencia de los antecedentes, si no tomamos postura crítica frente a lo que se escribe. Según Torres (2005), los semilleros de la Universidad Santo Tomás (USTA):

Se conciben como un grupo de estudio que se dedica al conocimiento, profundización o investigación de un tema, proyecto o problema, dentro de un área del conocimiento o disciplina científica. Entre sus principios está el trabajo en equipo, la solidaridad, la resolución alternativa de conflictos y el liderazgo (p. 12).

En el caso particular de la Facultad de Contaduría Pública de la Universidad Santo Tomás, se ha logrado una importante participación de estudiantes en diferentes proyectos de investigación, lo cual ha fortalecido el proceso de investigación formativa (González, 2006), "entendiendo esta como la generación de una cultura investigativa a partir del desarrollo de habilidades y aptitudes en esta área y el trabajo adelantado por los semilleros de investigación" (Universidad Santo Tomás, 2008, p. 2).

8 De acuerdo con Hernández y López (citado en Valero y Patiño, 2012) cultura académica es "La discusión racional, la tradición escrita y la prefiguración de las acciones; como una manera de reconocer la existencia de diferentes puntos de vista, sólidamente argumentados y en muchos de los casos decantados en publicaciones científicas, ponencias, simposios y demás; con el fin de aportar a un contexto particular". (p. 177) 
Por lo anterior, teniendo en cuenta que en los semilleros de investigación se pretende mediar en la construcción de nuevos conocimientos, de acuerdo a los cambios constantes del entorno, mediante procesos interdisciplinares, es pertinente que dentro de la profesión contable se puedan establecer aquellos aspectos que permitan mejorar los criterios de evaluación y la evolución en la investigación, en una profesión catalogada como de 'bajo perfil' por aquellos profesionales y estudiantes de carreras asociadas a las ciencias básicas. No se trata de buscar una caracterización cuadriculada (centrada únicamente en los saberes académicos) que pretenda que el investigador se centre únicamente en el campo de la investigación, sino de encontrar aquellos espacios en los cuales el profesional crezca de forma equilibrada como ser humano, contribuyendo así a la generación de una sociedad más justa y consciente.

Cuando el estudiante de contaduría pública se enfoca en la investigación de aquellos saberes que enriquecen la profesión y contribuyen con la formación de profesionales más competitivos, como por ejemplo otras áreas del conocimiento económico y administrativo, se motivan a realizar críticas que permiten formar investigaciones interdisciplinares, dirigidas a diferentes áreas del conocimiento (contable, económico, político, social y cultural). Los investigadores van formando nuevos campos y relaciones mediante las cuales es factible incrementar el número de proyectos que busquen contribuir con la solución de los problemas de la sociedad.

\section{Diseño metodológico}

\section{Enfoque metodológico}

Para estudiar el estado de los semilleros de investigación activos en las facultades de contaduría del país, se requirió un abordaje tanto cuantitativo como cualitativo. De acuerdo con Bonilla y Sehk (1997), la investigación cuantitativa parte de cuerpos teóricos, los cuales permiten formar hipótesis del problema en cuestión. Para el caso en particular, a partir de las hipótesis 
se procedió a la recolección de información primaria medible, y luego al análisis de la información, para finalmente revelar los resultados.

Se requirió información básica que reconociera las cualidades de los semilleros; por ello, dentro de la encuesta se tuvieron en cuenta preguntas semiabiertas para obtener información específica. Bonilla y Sehk (1997) mencionan que la principal característica de la investigación cualitativa es "su interés por captar la realidad social a través de los ojos de la gente que está siendo estudiada” (p. 47).

Desde este punto de vista, fue pertinente interrogar a los coordinadores o líderes de cada semillero y participar en reuniones y/o actividades realizadas por los grupos objeto de estudio, para obtener así información de primera mano. La combinación de los métodos de investigación cualitativos y cuantitativos, permitió la obtención de datos relevantes para la investigación los cuales se describen a continuación:

- La investigación cualitativa arrojó datos sobre los incentivos que tienen los estudiantes para ingresar a los semilleros de investigación, la estructura interna de los semilleros, líneas de investigación, beneficios que se les otorgan a los estudiantes por su labor (puede que no sean netamente monetarios), capacitación que se le otorga a los estudiantes investigadores para que desarrollen habilidades necesarias para la elaboración de trabajos de investigación, entre otros.

- La metodología cuantitativa requiere que entre los elementos del problema de investigación exista una relación cuya naturaleza sea lineal (Hernández, Fernández y Baptista, 2008). Algunos ejemplos de información cuantitativa que se obtuvieron a partir de esta investigación fueron: número de estudiantes en los semilleros; número de estudiantes por línea de investigación; características de los estudiantes como género, edad, semestre y promedio; productividad que tienen los semilleros en revistas indexadas, no indexadas, nacionales e internaciones; así como participación en ponencias nacionales e internacionales, entre otros. 


\section{Población o muestra seleccionada}

La población objeto de estudio en esta investigación fueron los semilleros de investigación en los programas de contaduría pública del país. Es necesario aclarar que debido a las dinámicas de la investigación es poco práctico indagar todos los programas. Por esta razón se tomó una muestra significativa, a partir de la información obtenida del Sistema Nacional de Información de la Educación Superior (SNIES, 2013), teniendo en cuenta los siguientes criterios:

- Los programas académicos de contaduría pública por revisar serán los que se encuentren ubicados en Bogotá, Medellín, Manizales, Cali, Bucaramanga y Cartagena, por ser ciudades principales, y algunas de ellas con mayor número de programas académicos de contaduría pública (ver tabla 3).

- Dichos programas deben contar con registro calificado.

- Los programas académicos deben ser universitarios.

La metodología de los programas debe ser presencial.

Tabla 3. Ciudades objeto de estudio

\begin{tabular}{c|c}
\hline Ciudad & No. de programas de contaduría pública a escala profesional \\
\hline Bogotá & 18 \\
\hline Bucaramanga & 5 \\
\hline Cali & 8 \\
\hline Cartagena & 6 \\
\hline Medellín & 8 \\
\hline Manizales & 1 \\
\hline
\end{tabular}

Fuente: elaboración propia a partir de Patiño y Santos (2009) y el Sistema Nacional de Información de la Educación Superior (SNIES, s. f.)

Para el desarrollo de este proyecto se realizaron encuestas con preguntas que dieron como resultado información estadístico-matemática (cuantitativa), así como información cualitativa. Dos claros ejemplos de información 
estadístico-matemática serían 1) el número de semilleros de contabilidad en cada una de los facultades objeto de estudio, estableciendo las ciudades donde mayor número de semilleros existen; y 2) información relacionada con las líneas de investigación y su razón de ser en cada contexto. Estos datos permitieron deducir cuáles son las temáticas más investigadas en los semilleros de las facultades de contaduría pública del país.

\section{Fuentes de información}

La información de esta investigación proviene de fuentes tanto primarias como secundarias. Las fuentes primarias abarcan las encuestas y la participación directa en actividades o reuniones realizadas con los semilleros, las cuales se efectuaron en dos etapas: en la primera etapa se buscó contactar a los encuestados por medio de tecnologías de información y comunicación (TIC). En la segunda etapa se llevó a cabo la encuesta y se participó en una o más actividades realizadas por el semillero estudiado. Todo ello se logró a través de salidas de campo. Por su parte, las fuentes secundarias comprenden el estudio sobre términos que fueron necesarios para el desarrollo de la investigación, con base en diversos autores.

\section{Técnicas de investigación}

Se utilizaron la técnica documental y la técnica de campo. La primera abarca las referencias a diversos autores cuyas teorías brindaron soporte a la investigación. La segunda permitió la observación en contacto directo con el docente coordinador y con el estudiante coordinador del semillero objeto de análisis, además del acopio de testimonios que permitieron confrontar la teoría con la práctica en la búsqueda de la información. Según Rojas (2002), la técnica de campo se basa en la información del sujeto objeto de estudio, adquirida por medio de un instrumento.

\section{Instrumentos}

Se desarrolló una encuesta para docentes (anexo 1) y una para estudiantes (anexo 2), ambas con preguntas cerradas y semiabiertas, con el fin de 
obtener la información primaria necesaria para el desarrollo del objetivo general y, así, facilitar la tabulación de la información y construcción de la base de datos.

\section{Sistematización de la información}

Se organizó, tabuló y analizó la información obtenida a través de la encuentra aplicada a docentes coordinadores y estudiantes líderes de cada semillero, con el fin de concluir las características más relevantes de los semilleros de contaduría pública. La encuesta arrojó información sobre los siguientes puntos.

1. Líneas de investigación: Estableciendo las principales áreas o temáticas de investigación en contabilidad o en contaduría pública.

2. Características principales de los integrantes de los semilleros

2.1. Género

2.2. Edad

2.3. Semestre

2.4. Promedio académico

3. Productividad

3.1. Publicación en revista indexada

3.2. Publicación en revista no indexada

3.3. Ponencias nacionales

3.4. Ponencias internacionales 
4. Financiación

\subsection{Financiación institucional}

4.2. Financiación propia del semillero

5. Actividades extracurriculares

\subsection{Normas APA}

\subsection{Expresión oral}

\subsection{Bases de datos}

5.4. Métodos de investigación

\subsection{Cine foros}

De igual modo, fue necesario indagar sobre los siguientes aspectos:

- Las principales posturas o enfoques epistemológicos ${ }^{9}$ que utilizan los semilleros en la realización de las investigaciones y en la construcción y desarrollo de las líneas de investigación;

- el tipo de estructura que existe al interior de cada semillero;

- beneficios que reciben los estudiantes por participar en estos grupos;

- la existencia (o no) de políticas que regulen el semillero;

\footnotetext{
9 Larrinaga (1999) afirma que las perspectivas de investigación son: el funcionalismo, que trata sobre el método hipotético-deductivo y la separación teorías-observaciones; el interpretativo, basado en la explicación científica, en la etnografía y en los casos de estudio; el crítico, fundamentado en la negación, en lo histórico y en los casos de estudio; y el poder, basado en la relatividad, en la verdad a través de la historia, en la arqueología y en la genealogía.
} 
- la realización (o no) de convocatorias para seleccionar a los estudiantes interesados en ingresar al semillero, entre otras.

Las respuestas brindaron información útil para caracterizar una proporción significativa de semilleros contables en el país, y así poder construir una base de datos que contribuyera a la realización de investigaciones interinstitucionales.

\section{Análisis de la información}

Una vez se obtuvo la base de datos de las universidades en las cuales existen semilleros de investigación en las ciudades de Bogotá, Cali, Medellín, Bucaramanga, Cartagena y Manizales (anexo 3), se evidenció que había un total de 46 semilleros formados como grupos de investigación en el ámbito institucional, y grupos de estudiantes con iniciativas y retos en este campo. Se procedió a realizar el contacto con los responsables (docentes y estudiantes coordinadores) en el desarrollo de las actividades de dichos grupos; como resultado, se logró obtener contacto con el $67 \%$ de la muestra objetivo, de la cual solamente fue posible contactar y entrevistar a un total de 20 semilleros de investigación a escala nacional.

La base de datos obtenida, junto con las encuestas realizadas, permitió establecer cuáles son las principales características de los semilleros de investigación de las facultades de contaduría pública de las universidades en el ámbito nacional. Los resultados mostraron lo siguiente:

En promedio, los docentes investigadores que conforman los semilleros de investigación son entre 2 y 3 , para un $45 \%$ de los encuestados. En segundo lugar aparece la opción 3 a 5, con un $30 \%$ del total de encuestas realizadas. Otras opciones tienen un porcentaje inferior al $15 \%$. Todo ello indica que los semilleros de investigación no cuentan con más de 7 docentes investigadores en promedio ni tampoco con uno solo, lo cual es importante resaltar, puesto que revela la labor que algunos docentes están tratando de impartir a sus estudiantes. 
1. ¿Cuántos docentes investigadores tiene el semillero?

Figura 1.

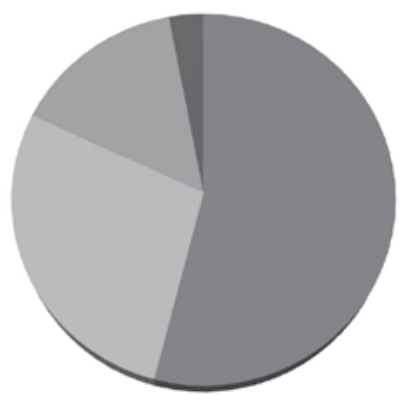

घ1 1 de 2 a 3 de 3 a 5 de 5 a 7 de 7 a 10 Otros

Fuente: elaboración propia a partir de los datos obtenidos en la encuesta.

2. ¿El semillero, además de contar con el apoyo de los docentes investigadores, cuenta con la ayuda de los demás docentes de la Facultad de Contaduría para el desarrollo de las investigaciones?

Figura 2.

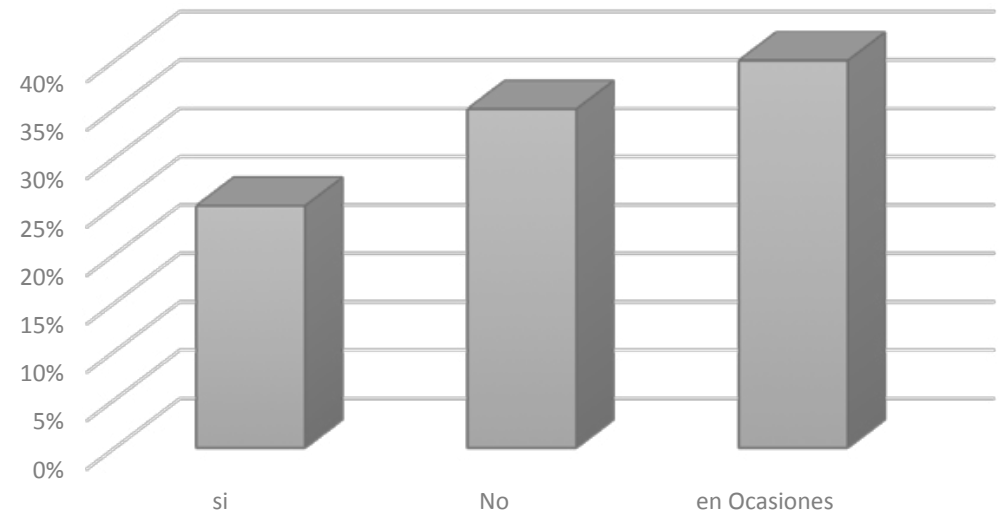

Fuente: elaboración propia a partir de los datos obtenidos en la encuesta. 
Los datos que arroja esta pregunta indican que el $40 \%$ de los semilleros cuenta en ocasiones con la ayuda de otros docentes de la facultad (distintos a los que pertenecen al semillero) para la elaboración de proyectos de investigación, y el $35 \%$ no cuenta con ninguna ayuda, lo que refleja que los otros docentes de la facultad no apoyan esta labor.

3. ¿Cuántos estudiantes pertenecen al semillero?

Figura 3.

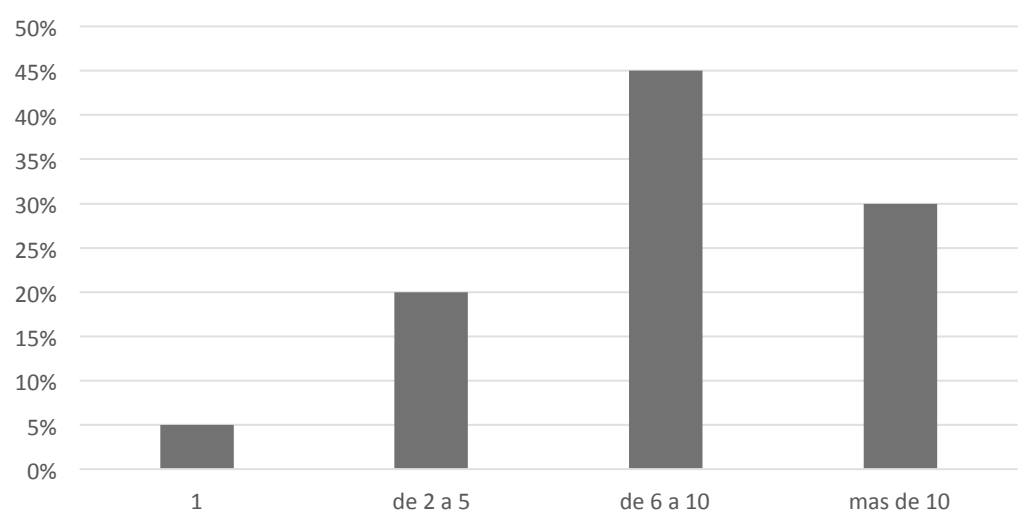

Fuente: elaboración propia a partir de los datos obtenidos en la encuesta.

Del total de semilleros de investigación encuestados, el $45 \%$ tiene en promedio 6 a 10 estudiantes; un $30 \%$ cuenta con una cantidad de 10 o más estudiantes; el $20 \%$, con un total de 2 a 5 ; y el $5 \%$, con un solo estudiante. 
4. ¿Cuántos estudiantes del semillero son mujeres?

Figura 4.

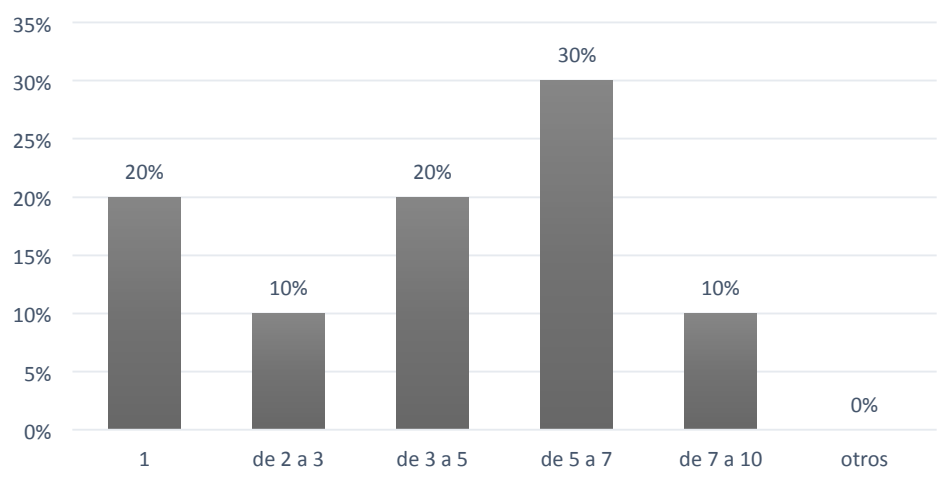

Fuente: elaboración propia a partir de los datos obtenidos en la encuesta.

El promedio de mujeres integrantes en los semilleros es alto. El resultado que proyectan las encuestas indica que el $40 \%$ de los semilleros tiene en mayor cantidad estudiantes mujeres.

5. ¿Cuántos estudiantes del semillero son hombres?

Figura 5.

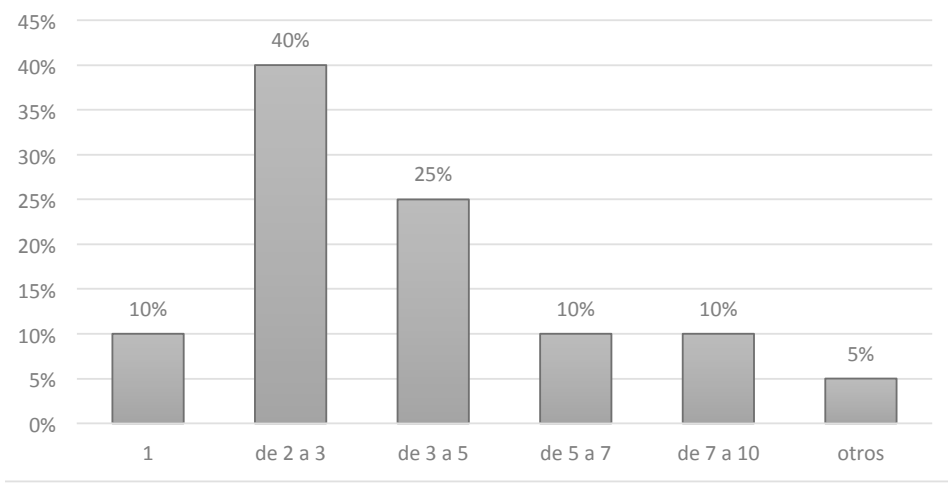

Fuente: elaboración propia a partir de los datos obtenidos en la encuesta. 
La cantidad de hombres que integran los semilleros de investigación es menor. En las encuestas realizadas, el $40 \%$ muestra que, en promedio, hay solamente de 2 a 3 estudiantes hombres, en comparación con la cantidad de integrantes.

6. ¿Cuál es la edad promedio de los estudiantes del semillero?

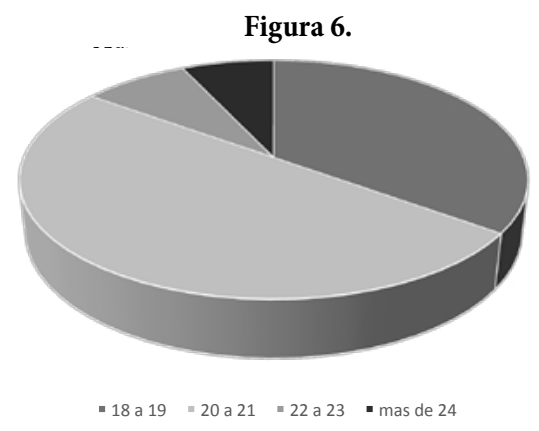

Fuente: elaboración propia a partir de los datos obtenidos en la encuesta.

El $50 \%$ de los estudiantes que integran los semilleros de investigación tienen entre 20 y 21 años; un $35 \%$, entre 18 y 19 años; y un $15 \%$ corresponde a las demás opciones.

7. ¿Cuál es el semestre promedio que cursan los estudiantes pertenecientes al semillero?

Figura 7.

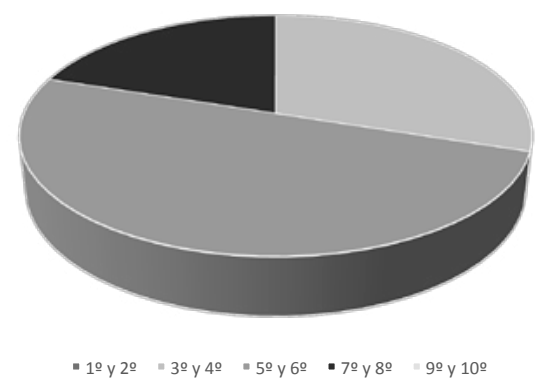

Fuente: elaboración propia a partir de los datos obtenidos en la encuesta. 
Según el $35 \%$ de los encuestados, el $50 \%$ de los integrantes de sus semilleros se encontraba (en el momento de la encuesta) entre V y VI semestre; el $30 \%$, entre III y IV; y el $20 \%$, en VII y VIII. Estos porcentajes reflejan que los estudiantes integrantes están cursando semestres avanzados, por lo cual tienen mayor claridad sobre la línea de investigación que les gustaría seguir, además de una opinión crítica sobre los temas que estén afectando la profesión.

8. ¿Cuál es el promedio académico general de los estudiantes del semillero?

Figura 8.

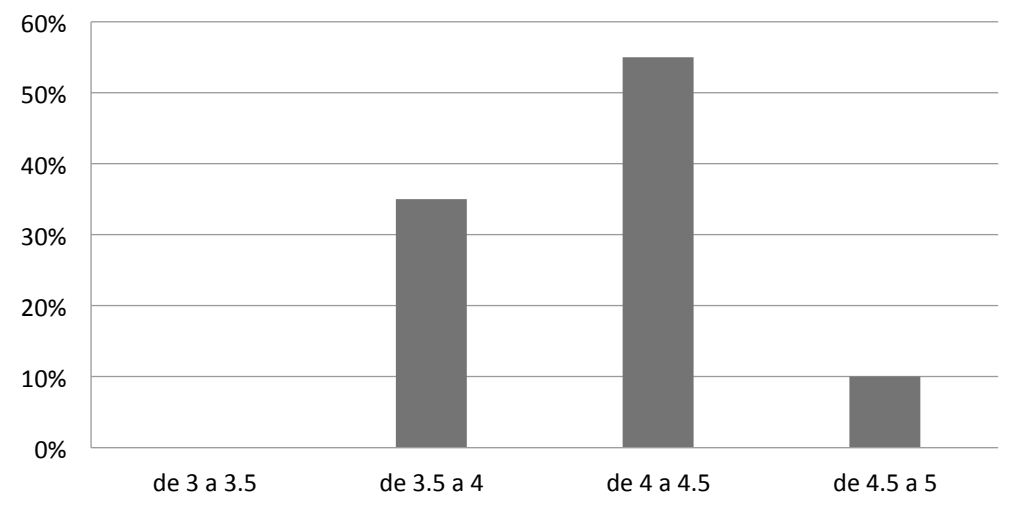

Fuente: elaboración propia a partir de los datos obtenidos en la encuesta.

El promedio académico de los estudiantes que integran los semilleros se encuentra entre 4 y 4,5 , según el $55 \%$ de los encuestados, lo que indica que los estudiantes tienen un buen rendimiento académico que les permite hacer parte de un grupo con compromiso y responsabilidad. 
9. ¿Existe una planeación estratégica y organigrama dentro del semillero?

Figura 9.

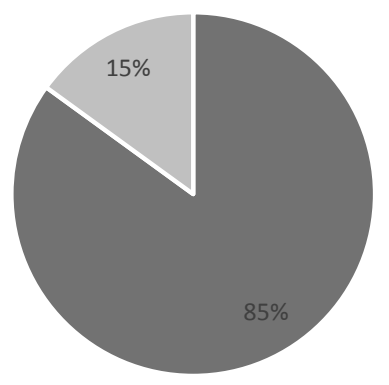

Fuente: elaboración propia a partir de los datos obtenidos en la encuesta.

El $85 \%$ del total de encuestados sí tiene un planeación estratégica y organigrama de su semillero de investigación, lo que refleja que sí están organizados formalmente y tienen fuertes bases de aspectos administrativos.

10.¿Existen políticas que regulen el semillero?

Figura 10.

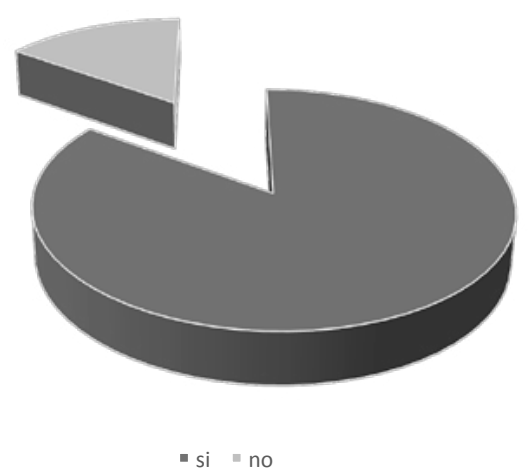

Fuente: elaboración propia a partir de los datos obtenidos en la encuesta. 
$\mathrm{Al}$ igual que la pregunta anterior, el $85 \%$ de los semilleros encuestados sí cuenta con políticas que regulan su semillero.

11. ¿Con qué frecuencia se realizan las reuniones entre los integrantes del semillero?

Figura 11.

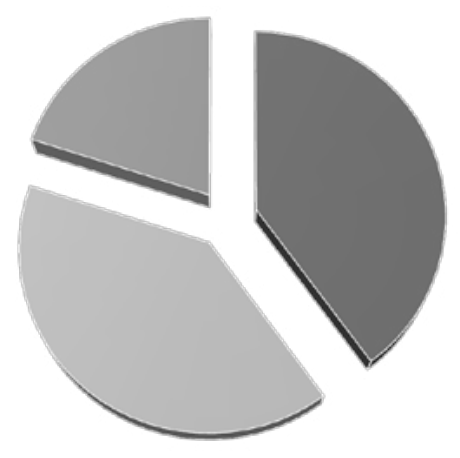

- Semanal =Quincenal - Mensual

Fuente: elaboración propia a partir de los datos obtenidos en la encuesta.

El $40 \%$ de los encuestados afirma que se reúnen semanalmente, para revisar los avances y el estado de sus actividades; el otro $40 \%$ se reúne quincenalmente; y el $20 \%$ restante se reúne mensualmente, ya que tienen dificultades por situaciones laborales, falta de tiempo libre, entre otros. 
12. ¿El semillero cuenta con un archivo físico o digital en el que se evidencie la trayectoria desde su creación?

Figura 12.

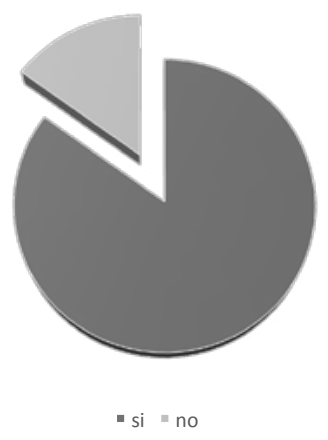

Fuente: elaboración propia a partir de los datos obtenidos en la encuesta.

El $85 \%$ de los encuestados afirmó que cuenta con un archivo fisico o digital que evidencia la trayectoria del semillero desde su creación — todas las actividades que han desarrollado, los estudiantes que han integrado el semillero, entre otros aspectos-.

13. ¿De qué forma se financia el semillero?

Figura 13.

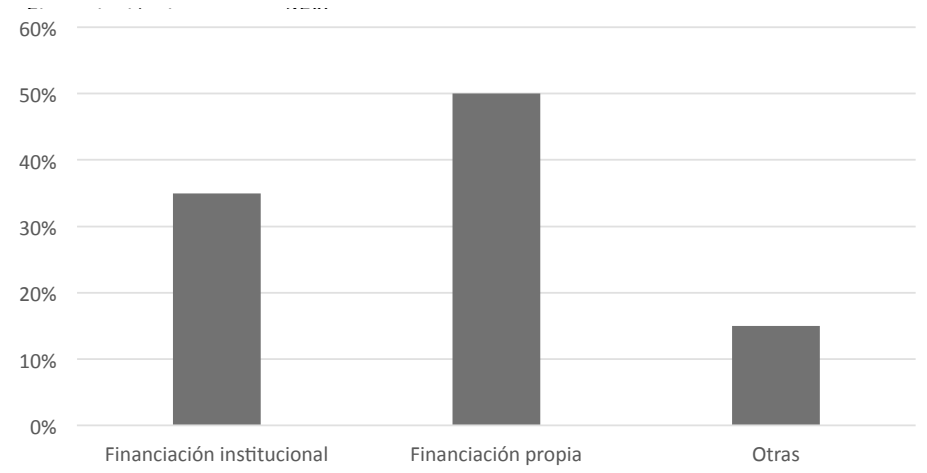

Fuente: elaboración propia a partir de los datos obtenidos en la encuesta. 
El $50 \%$ de los semilleros encuestados afirmó que se financia por cuenta propia, y el $35 \%$ cuenta con financiación institucional, lo que muestra que no cuentan con el apoyo suficiente para realizar más actividades.

14. ¿Cuál es la temática que considera más importante para investigar?

La temática más importante para los encuestados es la de medio ambiente y contabilidad, con un $40,7 \%$ de preferencia. Por otro lado, el $55,6 \%$ considera, en partes iguales, que las temáticas más importantes para investigar son educación contable, normas internacionales de contabilidad e impuestos.

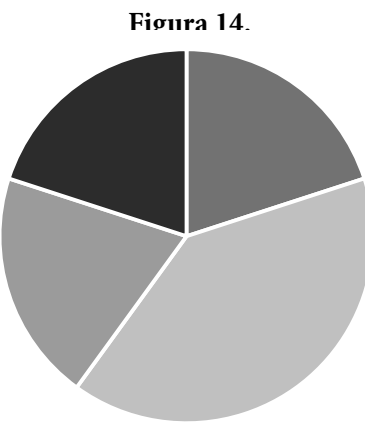

- Educación Contable $\quad$ Medio Ambiente y Contabilidad $\quad$ NIC/NIIF $\quad$ Otros

Fuente: elaboración propia a partir de los datos obtenidos en la encuesta.

15. ¿Qué tipo de actividades extracurriculares se realizan en el semillero?

Se considera importante que los integrantes de los semilleros tengan actividades extracurriculares para alimentar sus conocimientos y métodos de capacitación. El 26,7\% de los encuestados considera que el curso sobre normas APA es esencial, puesto que investigar requiere tener un conocimiento previo y claro sobre este tipo de temas; el 23,3\% considera también importante capacitarse en métodos de investigación; y el $20 \%$ opta por la capacitación en el uso de bases de datos, que son una de las herramientas más utilizadas para recopilar información. 
Figura 15.

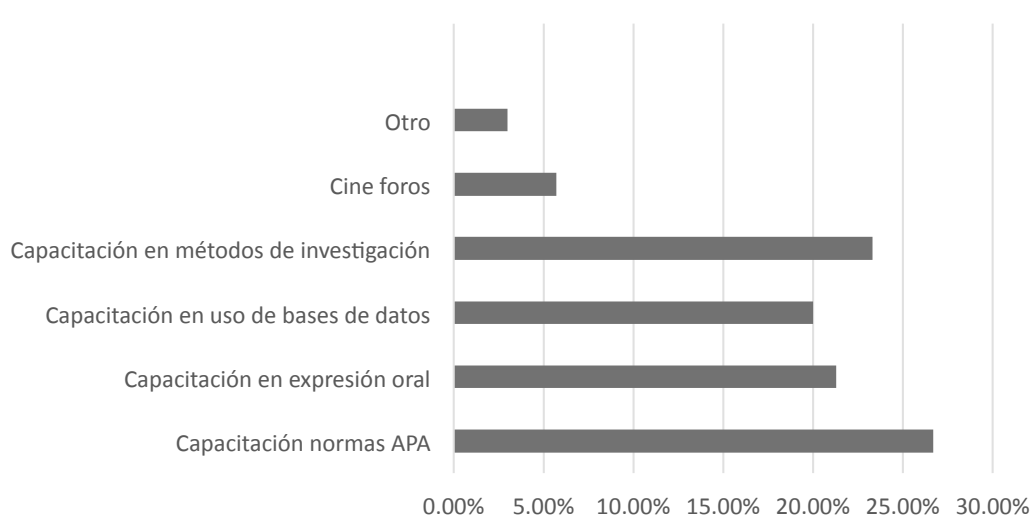

Fuente: elaboración propia a partir de los datos obtenidos en la encuesta.

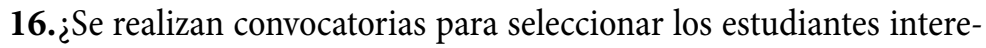
sados en ingresar?

Figura 16.

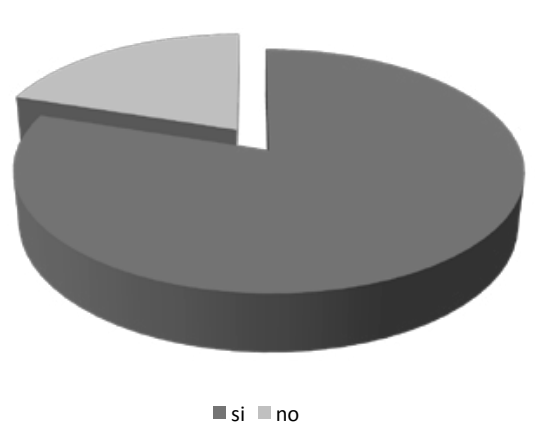

Fuente: elaboración propia a partir de los datos obtenidos en la encuesta.

El $80 \%$ de los semilleros de investigación realiza convocatorias para seleccionar a los estudiantes interesados. Estas convocatorias consisten en visitas a los salones de clase, donde se realizan charlas con algún 
integrante del semillero, por medio de los docentes o por medio de otros estudiantes.

17. El semillero ha tenido productividad en:

Figura 17.

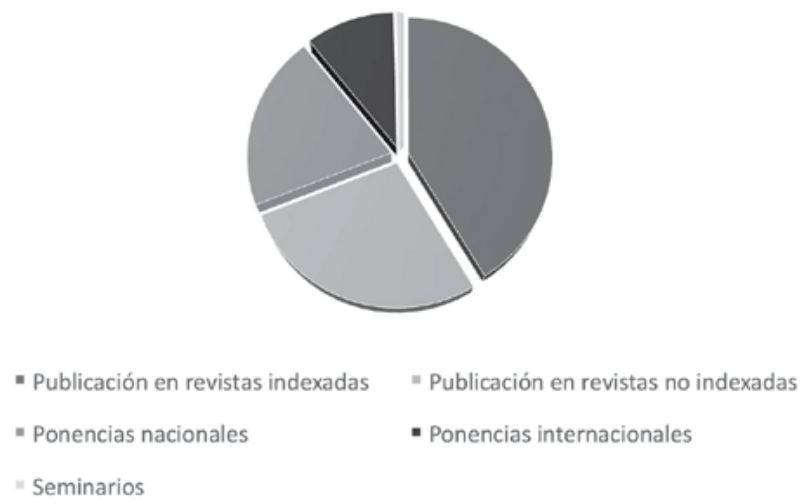

Fuente: elaboración propia a partir de los datos obtenidos en la encuesta.

De los semilleros encuestados, el $41,4 \%$ ha tenido publicaciones en revistas indexadas; el 27,6\%, publicaciones en revistas no indexadas; el $20,3 \%$ ha hecho ponencias a escala nacional; y el $10,3 \%$, en ponencias internacionales. Esto refleja avances importantes en productividad investigativa.

18. ¿Cuáles son los beneficios que reciben los estudiantes que pertenecen al semillero?

Según los docentes, el 33,3\% de los estudiantes recibe reconocimiento institucional; para el 20,8 \%, la permanencia en el semillero es válida como opción de grado u homologación de materias relacionadas con investigación; y el 16,7\% recibe descuento en la matrícula. Una remuneración financiera tiene menor porcentaje, dado que la permanencia en el semillero es por voluntad propia. 
Figura 18.

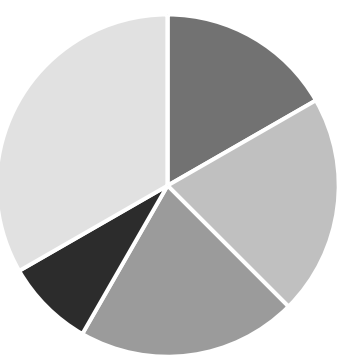

- Descuentos en la matricula - Opción de grado Homologación de materias

- Remuneración financiera $\quad$ Reconocimiento institucional $=$ Otros

Fuente: elaboración propia a partir de los datos obtenidos en la encuesta.

19. ¿El semillero ha tenido algún reconocimiento por parte de Colciencias?

Figura 19.

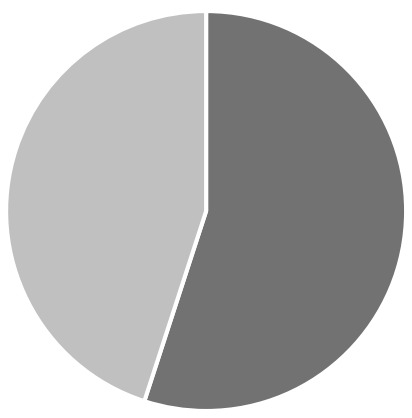

- si no

Fuente: elaboración propia a partir de los datos obtenidos en la encuesta.

El $55 \%$ de los semilleros encuestados ha tenido algún reconocimiento por parte de Colciencias, pues los semilleros pertenecen a la categoría de grupo de investigación, avalada por este estamento - aunque están pendientes de regategorización-. 
20. $¿$ El semillero pertenece a algún grupo registrado en Colciencias? $\mathrm{Si}$ su respuesta es no, por favor proceda con la pregunta 22.

El 55\% de los semilleros encuestados pertenece a un grupo registrado por Colciencias.

Figura 20.

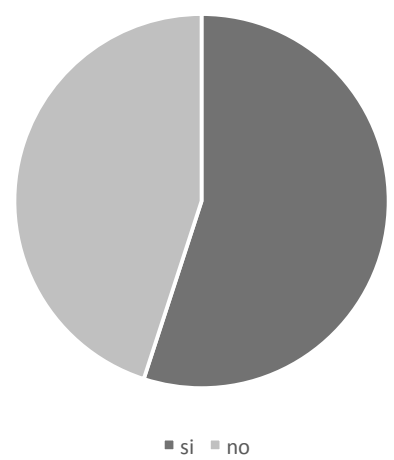

Fuente: elaboración propia a partir de los datos obtenidos en la encuesta.

21.¿A qué categoría de Colciencias pertenece el grupo de investigación?

Figura 21.

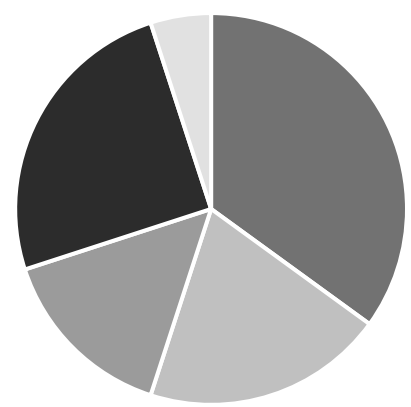

- Categoría A - Categoría B - Categoría C - Categoría D Registrado

Fuente: elaboración propia a partir de los datos obtenidos en la encuesta. 
De los encuestados, el 35\% pertenece a la categoría A; el $20 \%$, a la categoría B; el $15 \%$, a la categoría C; el $25 \%$, a la categoría D (otra); y el $5 \%$ no está registrado.

22. ¿Con qué otras disciplinas del conocimiento interactúa el semillero?

Figura 22.

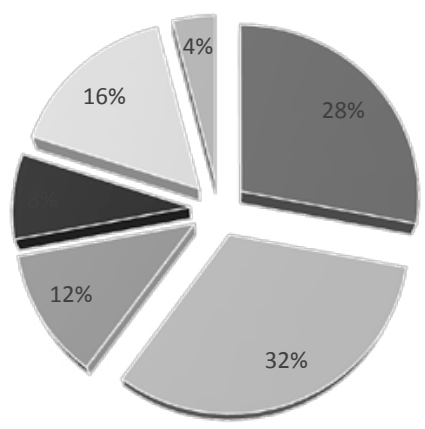

$$
\begin{aligned}
& \text { - Economía } \\
& \text { - Administración } \\
& \text { - Estadística } \\
& \text { - Derecho } \\
& \text { - Ingenierías } \\
& \text { - Ninguna }
\end{aligned}
$$

Fuente: elaboración propia a partir de los datos obtenidos en la encuesta.

Los semilleros encuestados indican que con la disciplina que más interactúan es Administración, en un 32\%; Economía, $28 \%$; Ingeniería, $16 \%$; Estadística, $12 \%$; Derecho, $8 \%$; y ninguna, $4 \%$. Esto muestra que los semilleros están interesados en trabajar con otras disciplinas para realizar investigaciones de forma conjunta.

23. ¿En el semillero existe trabajo interinstitucional?

El $60 \%$ de los semilleros no realiza trabajo interinstitucional con otros semilleros de investigación de facultades de contaduría pública de las universidades. 
Figura 23.

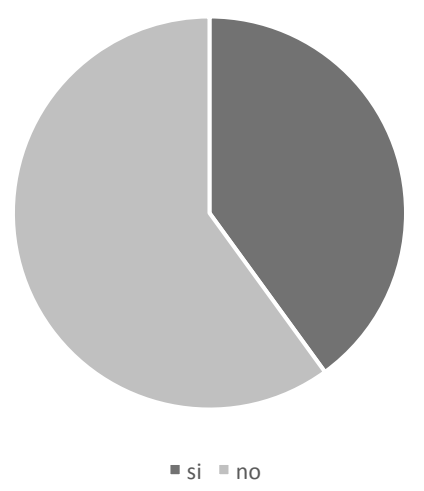

Fuente: elaboración propia a partir de los datos obtenidos en la encuesta

Los siguientes son los resultados derivados de trece encuestas realizadas a los estudiantes coordinadores de los semilleros de investigación de las universidades ubicadas en las ciudades de Bogotá, Medellín, Cali, Manizales, Bucaramanga y Cartagena.

1. ¿Qué le motivó a ingresar al semillero?

Figura 24 .

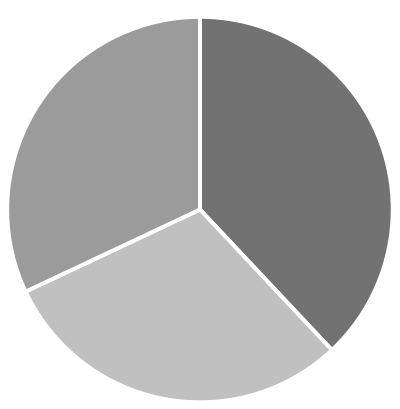

- Beneficios académicos - Adquirir nuevos conocimientos - Relaciones personales

Fuente: elaboración propia a partir de los datos obtenidos en la encuesta 
La principal motivación que tuvo el $38 \%$ de los estudiantes encuestados para ingresar a los semilleros de investigación fue la de los beneficios académicos que estos les brindan: reconocimiento institucional, homologación de materias, opción de grado o descuento en la matricula, según lo expresado en la pregunta 18 de la encuesta a los docentes coordinadores.

2. ¿Labora actualmente? Si su respuesta es no, por favor continúe con la pregunta 5 .

Figura 25.

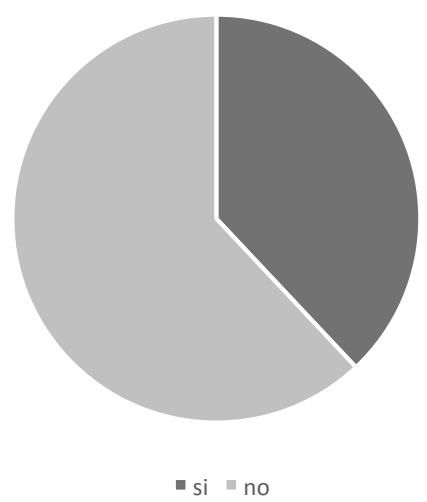

Fuente: elaboración propia a partir de los datos obtenidos en la encuesta.

El $62 \%$ de los estudiantes encuestados no labora actualmente, lo que permite deducir que estos estudiantes tienen más tiempo para dedicarse a este tipo de actividades. El $38 \%$ sí está laborando, lo que demuestra que el trabajo no es una evasiva para formar parte del semillero de investigación. 
3. ¿Cuántas horas al día trabaja?

Figura 26.

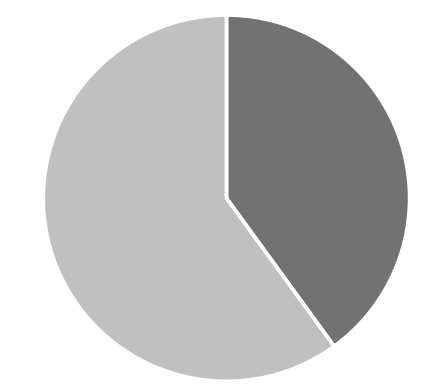

- de 5 a 8 horas diarias mas de 8 horas diarias

Fuente: elaboración propia a partir de los datos obtenidos en la encuesta.

Del $38 \%$ de participantes que trabajan, el $60 \%$ labora más de 8 horas diarias, lo que implica que tiene un horario extendido de trabajo. El $40 \%$ tiene un horario de trabajo promedio de 5 a 8 horas diarias. Este resultado indica el compromiso de los estudiantes que, aunque no poseen tiempo, contribuyen a las labores de los semilleros.

4. Rango de edad

Figura 27.

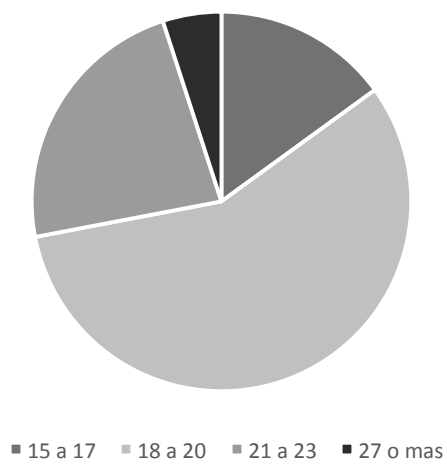

Fuente: elaboración propia a partir de los datos obtenidos en la encuesta. 
El $54 \%$ de los estudiantes encuestados tiene entre 18 y 20 años de edad; el $23 \%$, entre 21 y 23 años; el $15 \%$, entre 15 y 17; y el rango de edad con menor porcentaje es de 27 o más años, lo que explica que los jóvenes son los más interesados en hacer parte de los semilleros de investigación.

5. ¿Cuál es la temática que considera más importante para investigar?

El $46 \%$ de los estudiantes considera como temática más importante medio ambiente y contabilidad; el $23 \%$, impuestos; un $15 \%$, educación contable; y el otro $15 \%$, normas internacionales de contabilidad. Esta respuesta complementa la número 14 de la encuesta a los docentes coordinadores.

Figura 28.

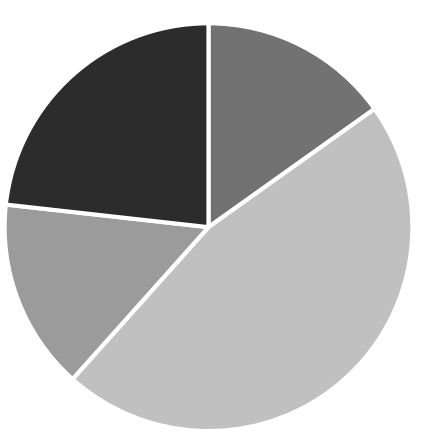

- Educación contable - Medio ambiente y contabilidad = NIC/NIIF - Otro

Fuente: elaboración propia a partir de los datos obtenidos en la encuesta. 
6. Si usted es estudiante coordinador, ¿tiene algún beneficio académico adicional distinto a sus compañeros?

Figura 29.

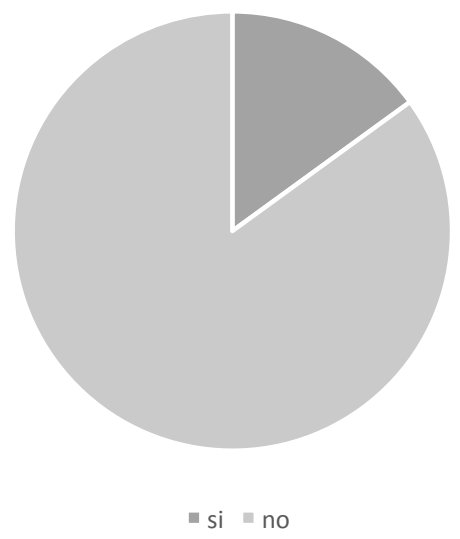

Fuente: elaboración propia a partir de los datos obtenidos en la encuesta.

El $85 \%$ de los estudiantes coordinadores encuestados no recibe ningún beneficio adicional o diferente a los demás integrantes del semillero. La respuesta expresa que este cargo es voluntario y que quién lo desempeña lo hace por compromiso.

7. ¿A través de qué medio se enteró de la existencia del semillero?

De acuerdo a los estudiantes encuestados, el $62 \%$ se enteró por medio de los docentes; el $23 \%$, por medio de compañeros; y el $15 \%$, por medio de las convocatorias que estos realizan. Lo anterior concluye que los docentes tienen una gran influencia en los estudiantes al momento de tomar la decisión de integrarse o no al semillero. 
172 ACTIVos | Mayra Alejandra Hoyos C., Maritza Rocha R., Oscar Yamith Duque C., Jeniffer Paola Rodríguez G., Sonia Milena Gómez R., Paola Andrea Leiva S.

Figura 30.

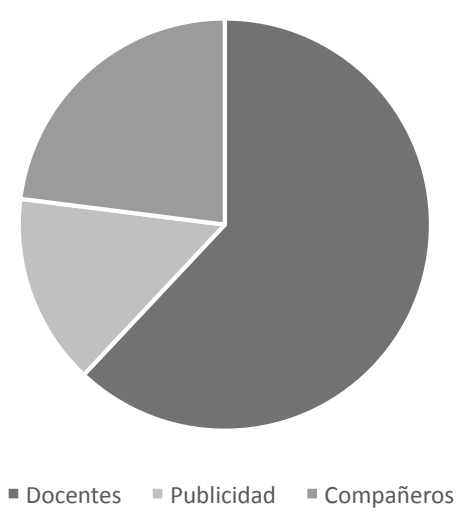

Fuente: elaboración propia a partir de los datos obtenidos en la encuesta.

8. ¿Con qué frecuencia se realizan las reuniones entre los integrantes del semillero?

Figura 31.

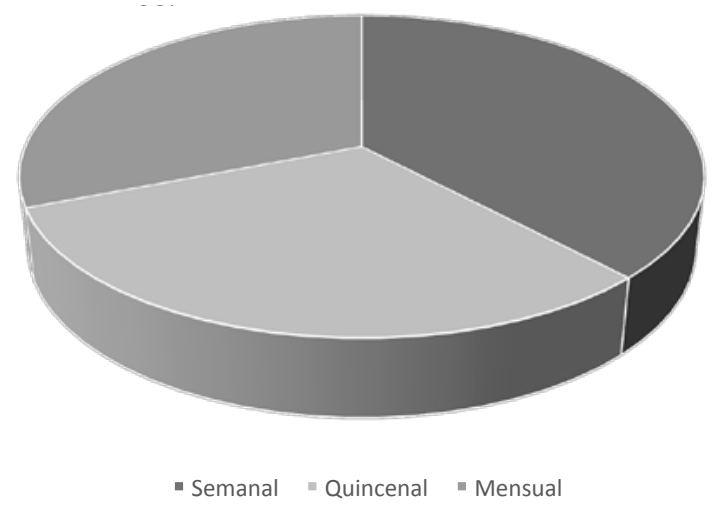

Fuente: elaboración propia a partir de los datos obtenidos en la encuesta. 
El $38 \%$ de los semilleros se reúnen semanalmente, para compartir los avances de las actividades que están realizando en el momento; el $31 \%$ semanalmente y otro $31 \%$ se reúne mensualmente, estos periodos tan extensos para la programación de reuniones, se explican en el hecho de las obligaciones laborales de los estudiantes que componen el semillero.

9. ¿En qué evento ha tenido la oportunidad de presentar sus investigaciones?

Figura 32.

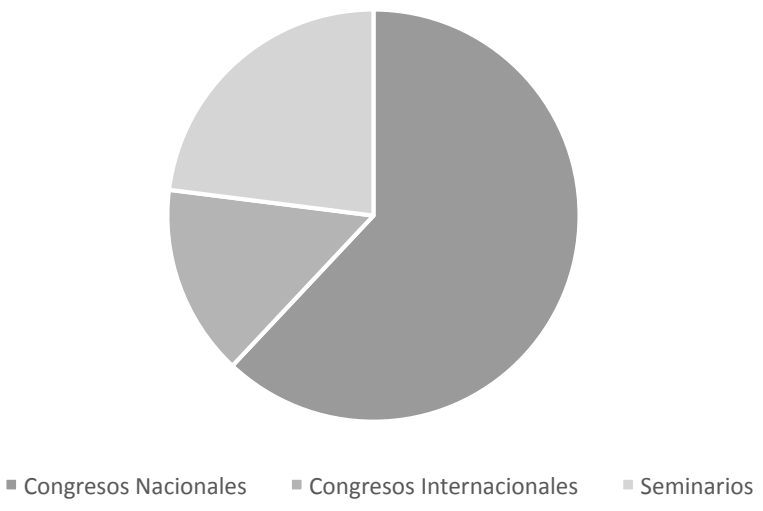

Fuente: elaboración propia a partir de los datos obtenidos en la encuesta.

El $62 \%$ de los estudiantes coordinadores ha presentado ponencias en congresos nacionales; el $23 \%$ ha presentado sus investigaciones en seminarios; y el $15 \%$ ha tenido la oportunidad de presentarse en congresos internacionales.

10. ¿Qué tipo de apoyo recibe por parte de los docentes de la facultad en el desarrollo de las investigaciones realizadas?

El $69 \%$ de los semilleros encuestados cuenta con la tutoría presencial de los docentes que integran el semillero; el $8 \%$ tiene tutorías con el docente por medios electrónicos; y el 23 \% no cuenta con el apoyo de ningún docente, lo 
cual es un aspecto preocupante, ya que los estudiantes están en proceso de formación y necesitan de un tutor que guíe sus trabajos de investigación.

\section{Figura 33.}

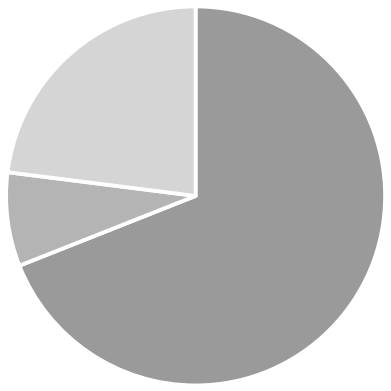

- Tutoría (presencial) = Tutoría (virtual) $=$ Ninguno

Fuente: elaboración propia a partir de los datos obtenidos en la encuesta.

11.¿Cuáles son sus retos o expectativas en el semillero?

Figura 34 .

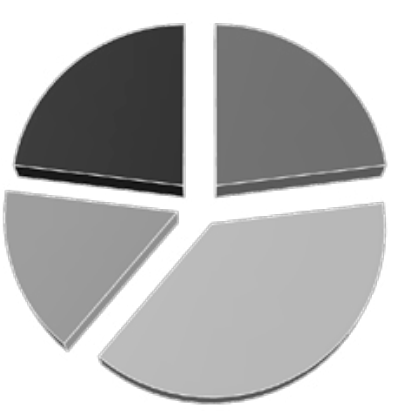

- Reto personal = Obtener beneficios - Permanencia en la universidad - Publicaciones

Fuente: elaboración propia a partir de los datos obtenidos en la encuesta.

El 38\% de los estudiantes busca obtener beneficios académicos; el 23\%, publicar sus investigaciones; y el otro $23 \%$, permanecer en el semillero como un reto personal, que le permita adquirir nuevas habilidades y desempeñar actividades por voluntad propia. 


\section{Anotaciones finales}

Esta investigación permitió identificar las principales características de un total de 20 semilleros de investigación activos de las facultades de contaduría pública de universidades ubicadas en Bogotá, Bucaramanga, Cali, Medellín, Cartagena y Manizales.

Es importante aclarar que en un principio se identificaron 46 semilleros de investigación activos en las facultades de contaduría pública en las principales ciudades de Colombia, pero solo se logró contactar a 31, y entrevistar solamente a 20 , hecho que se puede definir como una de las dificultades más importantes de la investigación, además de la dificultad para contactar a las personas indicadas, la falta de disposición de algunos para suministrar información privada y el ajuste de agendas para concretar las salidas de campo - que al final se realizaron en fechas académicamente inactivasTeniendo en cuenta los resultados de la investigación, se determinaron las principales características de los semilleros de investigación activos:

- En relación con la cantidad de estudiantes que los integran, la mayoría están conformados por 6 a 10. Por su parte, el $40 \%$ de los semilleros encuestados indicaron estar compuestos en su mayoría por mujeres.

- Los resultados de las encuestas a los docentes indicaron que el $35 \%$ está cursando, en promedio, entre V y VI semestre, y las edades circundan los 20 y 21 años de edad. Las encuestas de los estudiantes reflejan que el rango de mayor participación está entre los 18 y 20 años. Lo anterior muestra que los estudiantes integrantes están cursando semestres avanzados, lo cual les permite tener mayor claridad sobre la línea de investigación que les gustaría explorar, además de una opinión crítica sobre temas que estén afectando a la profesión.

- El $62 \%$ de los estudiantes encuestados no labora actualmente, lo que permite inferir una mayor disponibilidad de su parte para dedicarse a este tipo de actividades. Esto sugiere que los semilleros deben 
buscar estrategias para incorporar a los estudiantes que laboran, sin detrimento de su tiempo libre.

- Tomando como referencia las temáticas de mayor relevancia para los encuestados, aparece la de medio ambiente y contabilidad, seguida de educación contable, normas internacionales de contabilidad e impuestos, lo cual rompe el paradigma de los temas de mayor preferencia por parte de los contadores.

- Dentro de los beneficios que los estudiantes reciben por pertenecer a los semilleros, y de acuerdo con lo indicado por los docentes, reconocimiento institucional representa el mayor porcentaje, seguido de la posibilidad de tener opción de grado u homologación de materias relacionadas con investigación. En menor porcentaje reciben un descuento en la matrícula, dado que la idea de permanecer en el semillero es que sea por voluntad propia. Conforme a lo indicado por los estudiantes, la motivación a integrar y permanecer en el semillero está relacionada con los beneficios académicos que les ofrece la universidad, dejando de lado la oportunidad de adquirir habilidades en investigación para mejorar académicamente.

- Respecto a los docentes investigadores, solamente 2 o 3 conforman los semilleros, en promedio, lo que sugiere que estos grupos no han tomado la suficiente fuerza para incentivar el apoyo de los docentes investigadores, o que las labores no están claramente definidas. Asimismo, los datos indican que el $40 \%$ de los semilleros cuenta, en ocasiones, con la ayuda de otros docentes de la facultad (distintos a los que pertenecen al semillero) para la elaboración de proyectos de investigación, y el $35 \%$ no cuenta con ninguna ayuda, lo que refleja que los demás docentes de la facultad no están apoyando esta labor.

- De acuerdo con los estudiantes encuestados, el medio más frecuente por el cual se enteran de la existencia del semillero son los docentes, lo que permite concluir que son estos los más influyentes al momento de lograr integrantes en un semillero, y de tener espacios para 
desarrollar sus propuestas de investigación. Ahora, dicha influencia debe ser directamente proporcional al apoyo brindado a los estudiantes durante sus investigaciones, ya que el $23 \%$ de los encuestados no cuenta con la asesoría de un tutor. Esta cifra es preocupante, ya que los estudiantes están en proceso de formación y necesitan de un guía en el proceso.

- En cuanto al apoyo institucional, el 50\% de los encuestados se financian con recursos propios, mediante actividades culturales y de integración. Así pues, es importante que las universidades busquen la manera de incorporar en sus presupuestos mayores recursos para estos semilleros, que son el futuro de la investigación en Colombia. Además, al socializar los trabajos, ponencias y proyectos a escalas nacional e internacional, se pone en alto el nombre de las instituciones que representan, y de la facultad en especial.

- Las capacitaciones son importantes para que los estudiantes adquieran habilidades en temas como el manejo de bases de datos y expresión oral, entre otros. Esto refleja que las universidades, con el respaldo de áreas como Bienestar Universitario, o las unidades de investigación, sí están apoyando a los integrantes de estos semilleros y contribuyendo a la investigación formativa.

- Teniendo en cuenta los aspectos formales, institucionales y administrativos, el $85 \%$ del total de encuestados aplica la planeación estratégica, los organigramas, y cuentan con políticas que guían su conducta. Esto refleja que están organizados formalmente y que tienen fuertes bases de aspectos administrativos.

- Se construyó una base de datos (anexo 3) sobre los semilleros de investigación objeto de estudio, para futuras investigaciones y proyectos. En este sentido, se inició la creación de una red de semilleros, por medio del apoyo de la tecnología y de las redes sociales, que permita el contacto y la consolidación de proyectos interinstitucionales, con el objetivo de generar un fortalecimiento mutuo de 
todos los semilleros de investigación de las facultades y programas de contaduría pública en Colombia. En principio, se está elaborando una propuesta interna con dos universidades en Bogotá.

- Finalmente, la investigación deja interrogantes abiertos, que sería interesante cubrir en futuras investigaciones: ¿las universidades están incorporando en su estructura los semilleros de investigación? ¿Qué tantos integrantes de semillero han continuado con su línea de investigación o de docencia? ¿Cuántos y cuáles de los semilleros encuestados continúan funcionando después de cinco años?

\section{Referencias bibliográficas}

Banco de la República. (s. f.). Población colombiana. Recuperado de http://www. banrep.gov.co/es/poblacion

Banco Mundial. (s. f.). Investigadores dedicados a investigación y desarrollo (por cada millón de personas). Recuperado de http://datos.bancomundial.org/ indicador/SP.POP.SCIE.RD.P6/countries

Bonilla, E., \& Sehk, P. (1997). Más allá del dilema de los métodos. Bogotá: Norma.

Colombia. Decreto 80. Por el cual se organiza el sistema de educación postsecundaria (1980). Recuperado de http://repositorio.utp.edu.co/dspace/ bitstream/11059/1546/7/6583A662_anexotexto1.pd

Departamento Administrativo de Ciencia, Tecnología e Innovación (Colciencias). (2008). Colombia construye y siembra futuro. Política nacional de fomento a la investigación y la innovación. Recuperado de http://www.colciencias.gov. co/sites/default/files/recursos/documentos/colombiaconstruyesiembrafuturo20082011.pdf

Gómez, M. (2003). Algunos comentarios sobre la potencialidad de la investigacion en contabilidad. Innovar (21), 141.

Gonzalez, E. (2005). La investigación formativa como una posibilidad para articular las funciones universitarias de la investigacion, la extensión y la docencia. Revista de educación y pedagogía, (46), 106-108.

Grajales, T. (2000). El concepto de investigación. Recuperado de http://tgrajales. net/invesdefin.pdf 
Hernández, U. (2005). Propuesta curricular para la consolidación de los semilleros de investigación como espacios de formación temprana en investigación. Revista ieRed: Revista electrónica de la Red de Investigación Educativa [], 1 (2), 1-12.

Hernández, R., Fernández, C. \& Baptista, P. (2008). Metodología de la investigación. (4. ${ }^{\text {a }}$ d.). México: Mc Graw-Hill.

Hoyos, M. (2013). Incidencia de los semilleros de investigación en la formación integral del contador público. Ponencia presentada en el VIII Congreso de Estudiantes de Contaduría Pública. En Memorias del Seminario Contabilidad \& Humanismo. Bogotá: Universidad Santo Tomás.

Larrinaga, C. (1999). Perspectivas alternativas de investigación en contabilidad: Una revisión. Revista de Contabilidad, 2(3), 103-129.

Ministerio de Educacion Superior. (2010). Acreditación de la educación superior. Universia. Recuperado de http://encuentros.universia.net/CO/espanol/ficha480-informes.html

Patiño, R. \& Santos, G. (2009). La investigación formativa en los programas de contaduría pública: Caso Colombia. Capic Review, (7), 23-34.

Patiño, R., \& Santos, G. (2009b). Planes de estudio de contaduría pública en Colombia y las propuestas de formación profesional. Revista Internacional Legis de Contabilidad y Auditoría (37), 131-164.

Pineda, E. (2009). Orígenes y dinámicas de los semilleros de investigación en Colombia: La visión de los fundadores. En L. Molineros (Ed.), Los Semilleros de Investigación en Colombia. Ciudad:Popayán. Editorial: Universidad del Cauca Recuperado de http://www.uniatlantico.edu.co/uatlantico/sites/default/files/ investigacion/pdf/Libro\%20de\%20Semilleros.pdf

Quintero, J., Munévar Molina, R. A. \& Munévar Quintero, F. I. (2008, marzo 13). Smeilleros de investigación: una estratégia para la formación de investigadores. Universidad de la Sabana. Obtenido de http://educacionyeducadores. unisabana.edu.co/index.php/eye/article/view/716/1694

Restrepo, B. (2010). Conceptos y aplicaciones de la investigación formativa, y criterios para evaluar la investigación científica en sentido estricto. Recuperado de http:// desarrollo.ut.edu.co/tolima/hermesoft/portal/home_1/rec/arc_6674.pdf

Rojas, E. (2010). Orígenes y dinámica de los semilleros de investigación en Colombia. El Movimiento de semilleros de investigación visto desde la Universidad del Cauca. En L. Molineros (Ed.), Los Semilleros de Investigación 
en Colombia. Ciudad:Popayán. Editorial: Universidad del Cauca Recuperado dehttp://www.uniatlantico.edu.co/uatlantico/sites/default/files/investigacion/ pdf/Libro\%20de\%20Semilleros.pdf

Rojas, R. (2002). Investigación social: Teoría y Praxis. México: Plaza y Valdés.

Sistema Nacional de Información de la Educación Superior (SNIES). (s. f.). Consulte instituciones y programas del país. Recuperado de http://www.mineducacion. gov.co/sistemasdeinformacion/1735/w3-article-212396.html

Torres, M. (2005). Semilleros de investigación en la USTA. Recuperado de http:// investigacion.usta.edu.co/documents/1-10-2.pdf

Universidad Santo Tomás. (2008). Actualidad Investigativa No. 1. Bogotá: Universidad Santo Tomás.

Valero, G., \& Patiño, R. (2012). Los grupos de investigación contable reconocidos por Colciencias. Cuadernos de Contabilidad, 13(32), 175-201.

Vivas Ramos, D. R. (2010). Orígenes y dinámica de los semilleros de investigación en Colombia. Ponencia presentada en la instalación del VII Encuentro Nodal de Semilleros de Investigación, Bogotá, Junio 12 - 152010.

Zuluaga, L., Mosquera, J., \& Higuera, M. (2012). Procesos de formación de líderes investigadores:* Aplicado a los estudiantes del programa de Arquitectura de la Universidad de Pamplona. Revista Científica Guillermo Ockham, 10(2), 37-47. 